\title{
Pediatric Aerosol Therapy: New Devices and New Drugs
}

\author{
Bruce K Rubin MD MEngr MBA FAARC
}

\author{
Introduction \\ New Delivery Systems \\ Small-Volume Liquid Inhalers \\ Breath-Activated and Breath-Controlled Nebulizers \\ Aerosol Delivery to Infants and Toddlers \\ Engineered Particles \\ Novel Medications \\ Aerosol Antibiotics \\ Mucoactive Medications \\ Aerosol Surfactants \\ Anti-inflammatory Drugs \\ Aerosolized Peptides and Proteins \\ Prostacyclin Analogues for Pulmonary Hypertension \\ Medications for Treating Pain and Dyspnea \\ Aerosol Administration During Mechanical Ventilation \\ Aerosol Delivery Via High-Flow Nasal Cannula \\ Adherence to Therapy \\ Summary
}

The lung and conducting airways are ideal portals for drug delivery. The airways are easily accessible by oral or nasal inhalation; the airway and alveolar surface is large, allowing for drug dispersion; and many drugs do not cross the airway-blood barrier, permitting the use of higher topical drug doses for airway disease than would be practical with systemic administration. On the other hand, alveolar deposition of drugs allows rapid absorption into the pulmonary circulation and back to the left heart and systemic distribution, bypassing the intestinal tract and liver inactivation. Recently, there has been a feast of new aerosol devices and drug formulations that promise the effective delivery of an amazing array of medications far beyond pressurized metered-dose inhalers and nebulizers and asthma medicines. Key words: aerosol devices; nebulizers; children; medication adherence; gene therapy; antibiotics; mucolytics. [Respir Care 2011;56(9):1411-1421. (C) 2011 Daedalus Enterprises]

\section{Introduction}

Aerosol delivery of drugs has been used for thousands of years, through the inhalation of burning plants: notably,

Dr Rubin is affiliated with the Department of Pediatrics, Virginia Commonwealth University School of Medicine, Richmond, Virginia.

Dr Rubin presented a version of this paper at the 47th RESPIRATORY CARE Journal Conference, "Neonatal and Pediatric Respiratory Care: What Does the Future Hold?" held November 5-7, 2010, in Scottsdale, Arizona. tobacco. Aerosol delivery was revolutionized in the 1950 s with the development of efficient jet nebulizer devices ${ }^{1}$

\footnotetext{
Dr Rubin has disclosed relationships with Novartis, MAP Pharmaceuticals, Gilead, and Trudell Medical International.

Correspondence: Bruce K Rubin MD MEngr MBA FAARC, Department of Pediatrics, Virginia Commonwealth University School of Medicine, Richmond, VA 23298. E-mail: brubin@vcu.edu.
}

DOI: $10.4187 /$ respcare.01246 
Table 1. Novel Aerosol Devices

\begin{tabular}{|c|c|c|}
\hline Device & Advantages & Disadvantages \\
\hline $\begin{array}{l}\text { Breath-activated nebulizers } \\
\text { AeroEclipse }\end{array}$ & $\begin{array}{l}\text { Delivers medication only during inhalation } \\
\text { Less medication wasted }\end{array}$ & $\begin{array}{l}\text { Needs sufficient flow to trigger } \\
\text { Takes longer to deliver medication } \\
\text { More expensive }\end{array}$ \\
\hline $\begin{array}{l}\text { Breath-enhanced nebulizers } \\
\text { Adaptive aerosol delivery (iNeb) } \\
\text { AKITA patient-individualized therapy }\end{array}$ & $\begin{array}{l}\text { Targeted delivery } \\
\text { Less wasted medication } \\
\text { Delivery adapts to patient's breathing } \\
\text { Can monitor patient adherence }\end{array}$ & $\begin{array}{l}\text { Very expensive devices } \\
\text { Not ventilator enabled } \\
\text { Can be "confused" by incorrect use }\end{array}$ \\
\hline $\begin{array}{l}\text { Vibrating-mesh nebulizers } \\
\text { Aeroneb Go, Pro } \\
\text { Omron MicroAir } \\
\text { Pari eFlow } \\
\text { ODEM TouchSpray }\end{array}$ & $\begin{array}{l}\text { Fast, quiet, portable } \\
\text { Self-contained power source } \\
\text { Can optimize particle size for specific drugs }\end{array}$ & $\begin{array}{l}\text { More expensive } \\
\text { Not compatible with viscous liquids or those that } \\
\text { crystallize on drying } \\
\text { Cleaning can be difficult } \\
\text { Medication dosage must be adjusted if transition } \\
\text { from a jet nebulizer }\end{array}$ \\
\hline The Aerosol Hood ("Child Hood") & $\begin{array}{l}\text { Easy to apply } \\
\text { May be used for small infants in mild respiratory } \\
\text { distress }\end{array}$ & $\begin{array}{l}\text { Not well validated } \\
\text { Facial deposition and environmental } \\
\quad \text { contamination by aerosol } \\
\text { Unpredictable aerosol deposition }\end{array}$ \\
\hline $\begin{array}{l}\text { Metered-dose liquid inhalers } \\
\text { Respimat Soft Mist inhaler }\end{array}$ & $\begin{array}{l}\text { Easier to use than a pressurized metered-dose } \\
\text { inhaler } \\
\text { Gives feedback } \\
\text { Very effective aerosol delivery }\end{array}$ & $\begin{array}{l}\text { More expensive } \\
\text { Small dosing chamber } \\
\text { Not suitable for use with a mechanical ventilator }\end{array}$ \\
\hline $\begin{array}{l}\text { Engineered particles } \\
\text { Technospheres } \\
\text { PulmoSpheres }\end{array}$ & $\begin{array}{l}\text { Can use a very simple and inexpensive dry- } \\
\text { powder inhaler device } \\
\text { Breath-activated }\end{array}$ & $\begin{array}{l}\text { More difficult to manufacture particles } \\
\text { Not for use with all medications } \\
\text { May require larger number of inhalations then } \\
\text { usual dry-powder inhaler }\end{array}$ \\
\hline High-flow nasal cannula delivery & $\begin{array}{l}\text { Able to deliver drug to patient in respiratory } \\
\text { distress. } \\
\text { No need to stop oxygen to deliver medication }\end{array}$ & $\begin{array}{l}\text { No clinical data yet to support use or provide } \\
\text { dosing guidelines } \\
\text { May not be useful for some drugs, } \\
\text { Higher upper-airway deposition }\end{array}$ \\
\hline
\end{tabular}

and the pressurized metered-dose inhaler (pMDI). ${ }^{2}$ These are still the most common means of delivering aerosol medication for the treatment of asthma and COPD. In the past decade there have been advances in drug and device development that hold the promise to revolutionize aerosol drug delivery. Many of these novel devices can make drug delivery more precise, less wasteful, and potentially much easier for the youngest and most incapacitated of patients. An increased understanding of the pharmacokinetics and effects of aerosol drugs gives us opportunities to deliver a variety of novel medication using the lungs as a systemic portal. In keeping with the theme of this Journal Conference, this paper will focus on new devices and drugs that could become useful in neonatal and pediatric critical care.

\section{New Delivery Systems}

There are a large number of aerosol delivery systems that have been recently introduced to the market (Table 1). ${ }^{3}$ These include small-volume liquid inhalers, vibrating-mesh inhalers, smart nebulizers, and breath-controlled nebulizers. Each of these devices is likely to have a particular niche.

\section{Small-Volume Liquid Inhalers}

The Respimat Soft Mist Inhaler (Fig. 1) is a disposable device that does not require compressed air or electricity; the energy is provided by spring compression. ${ }^{4}$ It produces an aerosol for just over one second at a velocity of approximately 10 meters per second. ${ }^{5}$ This slow mist improves coordination, making it easier to use than a pMDI, with efficient drug delivery of approximately $40 \%$. It is used for administering $\beta$ agonist and anti-cholinergic medications in Europe, and it is expected that it will first be used for tiotropium when it is introduced in North America next year. There are several disadvantages to the Respimat. The small dosing chamber $(15 \mu \mathrm{L})$ limits the amount of medication. It is also necessary to coordinate actuation of the inhaler with inhalation, although the longer inhala- 


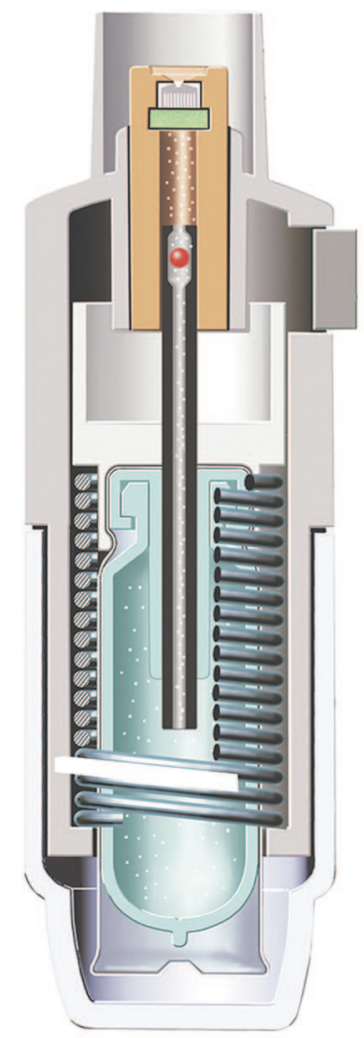

Fig. 1. The Respimat Soft Mist Inhaler is a small-volume liquid inhaler that does not require compressed air or electricity; the energy is provided by spring compression. (Courtesy of Boehringer Ingelheim.)

tion period is forgiving. ${ }^{6}$ Tiotropium delivered via the Respimat was shown to have a greater respirable aerosol mass for patients with COPD, compared to using the HandiHaler. $^{7}$

Vibrating-mesh technology uses a piezo (pressure-responsive) element that vibrates a precisely drilled mesh in contact with the drug, creating an aerosol. This can be optimized for different drugs by adjusting the pore size of the mesh, the aerosol chamber size, the reservoir size, and the output rate. ${ }^{8}$ In general these devices have a low residual volume, silent operation, and rapid output. They are small and portable and can be powered either by battery or alternating current; they are faster than jet nebulizers, and higher doses are possible. However, these devices are more expensive than classic jet nebulizers, ${ }^{8}$ so they may be most useful for expensive medications. Examples of the openmesh devices include the Aeroneb Go (Fig. 2), the Omron MicroAir (Fig. 3), and the Pari eFlow. The first use of vibrating-mesh technology has been the eFlow (called APIXNEB in Fig. 4, shown with the AKITA described below) device, used with aztreonam (Cayston, Gilead Sci-

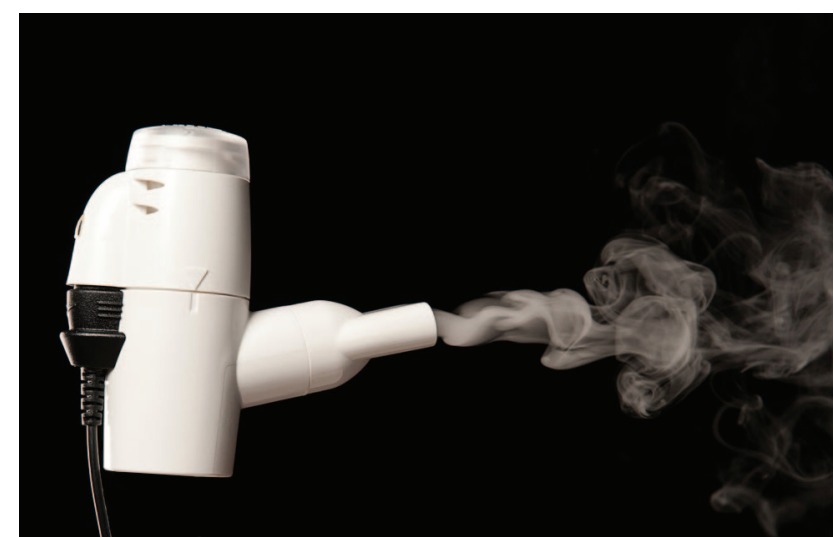

Fig. 2. The Aeroneb Go is an open-mesh, vibrating-mesh nebulizer. (Courtesy of Aerogen.)

ences, Foster City, California) for the treatment of cystic fibrosis $(\mathrm{CF})$ respiratory infections. ${ }^{9}$

There are challenges with using vibrating-mesh devices. They are not effective for delivering drugs in suspension or viscous drugs that can clog the pores. Drug or soap residue can be left in the pores, and it can be difficult to determine from the output of the device if these pores are clogged. Cleaning can be difficult, and the mesh needs to be handled gently during the cleaning process. It is also possible that the pressure vibrations can disrupt drug carrier complexes.

\section{Breath-Activated and Breath-Controlled Nebulizers}

Breath-activated nebulizers like the AeroEclipse (Trudell Medical International, London, Ontario, Canada) (Fig. 5) are a technology that senses the patient's inspiratory flow and delivers aerosol only when flow triggers the opening of a valve. These nebulizers decrease medication wastage but can increase delivery time.

Breath-controlled nebulizers use computer technology to determine a patient's inspiratory flow and volume, and use those to deliver the medication at the beginning of inhalation, allowing the inspired air at the end of inhalation to drive the aerosol deep into the airway. ${ }^{10}$ This permits improved dose precision, particularly to the smaller airways, and decreases upper-airway deposition. By using a slow inspiratory maneuver, larger particles can be deposited more efficiently. This may be important when large airway deposition is desirable, as when using $\beta$ agonist bronchodilators or inhaled surfactant. This can also reduce delivery time by allowing a lower dosage. Most breathcontrolled nebulizers have a low residual volume. Together this decreases waste, particularly for expensive medications such as peptides, which often have a larger particle size. A disadvantage of these nebulizers is they are more expensive than conventional jet nebulizers, although the 


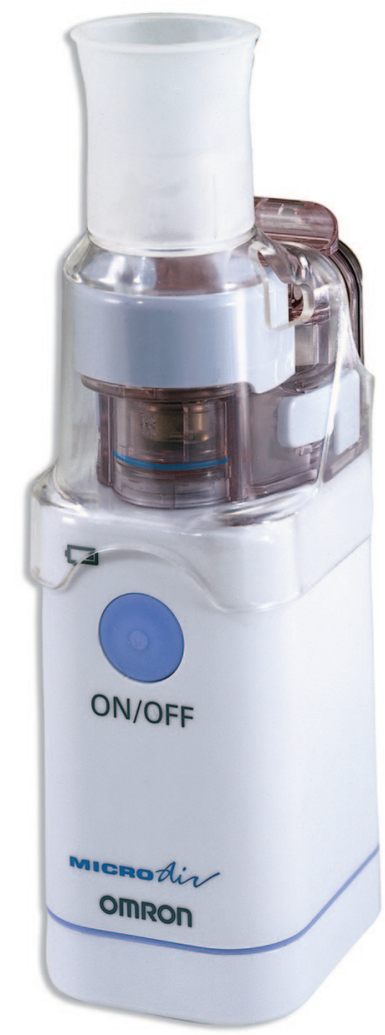

Fig. 3. The Omron MicroAir is an open-mesh, vibrating-mesh nebulizer. (Courtesy of Omron.)

cost may be absorbed by savings in reduced waste of expensive drugs.

Adaptive aerosol delivery nebulizer technology is a multiple-breath technology developed by Philips Respironics. The adaptive aerosol delivery device is preprogrammed with the inhalation dose. A computer "learns" how the patient is breathing and adapts to changes in this breathing pattern averaged over a series of breaths. Feedback is given to the patient when the dose is delivered, and there is a data logger that acts as an electronic diary to permit assessment of adherence. Adaptive aerosol delivery nebulizers aerosolize only on inhalation. They require a compressor, but they can deliver a larger volume of medication. Adaptive aerosol delivery nebulizers are well tolerated, and there is good inter-subject reproducibility. However, using an adaptive aerosol delivery device takes longer than delivering the same dose using a conventional nebulizer.

The AKITA (Activaero, Gemünden/Wohra, Germany) (see Fig. 4) is a device that delivers inspiratory flow at $12-15 \mathrm{~L} / \mathrm{min}$, allowing larger particles to navigate into the lung and bypass areas of obstruction. This can be coupled with a jet nebulizer or with a mesh device and can be used with an aerosol mask in small children. The controlled breathing permits high efficiency and low

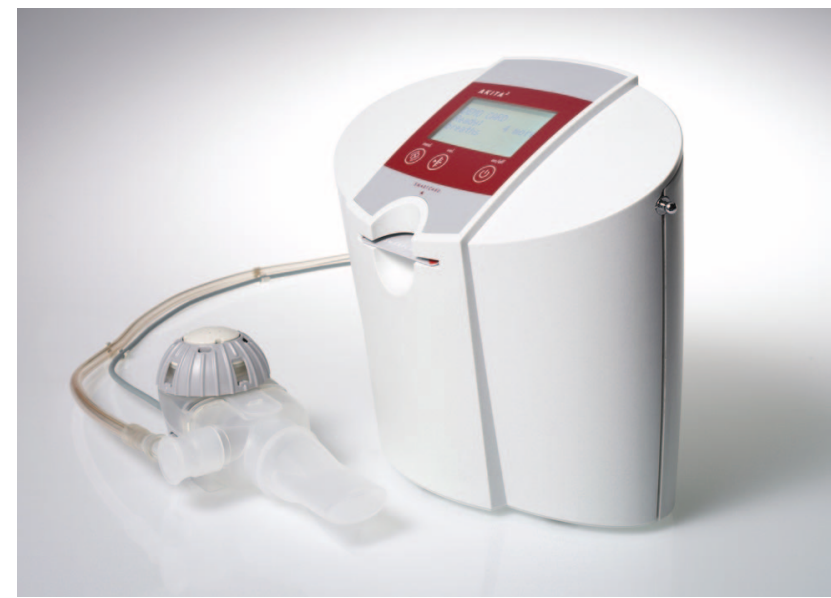

Fig. 4. The Pari eFlow (called APIXNEB when used with the AKITA) open-mesh, vibrating-mesh nebulizer paired with the Activaero AKITA JET nebulizer to individualize patient aerosol delivery using a computer algorithm and personal "Smart Cards." (Courtesy of Activaero.)

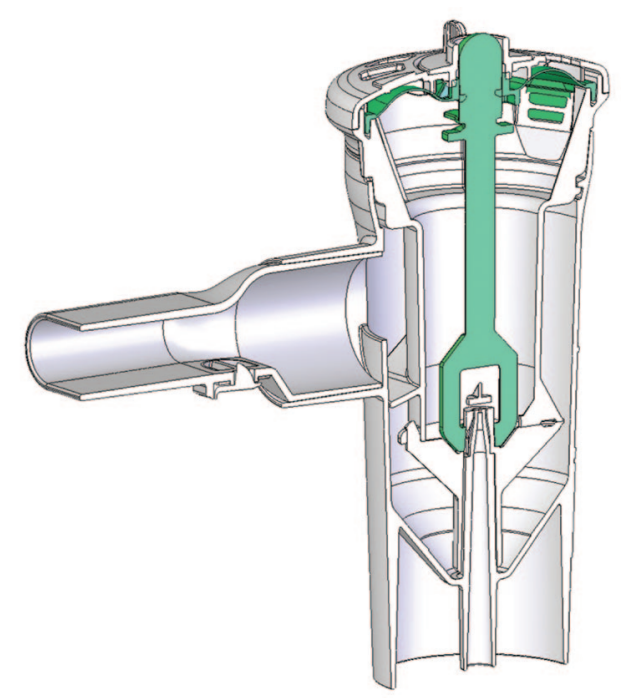

Fig. 5. The AeroEclipse nebulizer senses the patient's inspiratory flow and delivers aerosol only when flow triggers the opening of a valve. (Courtesy of Trudell Medical International.)

variability with individual breathing patterns, providing an appropriate dosing for different particle types. The "Smart Card" technology can calibrate the device as well as track adherence. ${ }^{11}$

\section{Aerosol Delivery to Infants and Toddlers}

Aerosol therapy works best if a patient is breathing quietly. Infants and toddlers who do not tolerate the use of an aerosol mask also do not tolerate blow-by. This will dramatically decrease drug deposition in the airway. ${ }^{12}$ Devices have been developed to deliver medication to the 


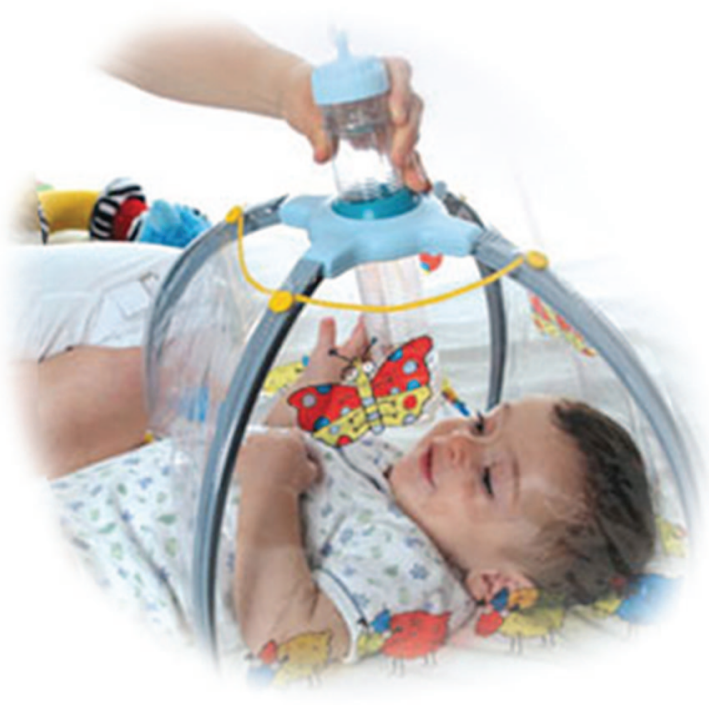

Fig. 6. The BabyAir delivers medication to the child using a hood that covers the child's head, coupled with an efficient nebulizer, allowing aerosol delivery while the child is asleep. (Courtesy of Baby's Breath.)

child using a hood that covers the child's head, coupled with an efficient nebulizer, allowing delivery while the child is asleep (BabyAir, Baby's Breath, Or-Akiva, Israel) (Fig. 6). ${ }^{13}$ There is also a device developed by the same group that incorporates the child's pacifier into an aerosol mask, soothing the child who sucks on the pacifier and allows the mask to rest on the face as the infant inhales through his or her nose.

\section{Engineered Particles}

Aerosol delivery not only depends on the patient and on the device but also on the particle geometry. This has led to the development of engineered particles that can be used with simple devices. An example of this is the technology now owned by Alkermes, which permits dry-powder delivery of low mass median aerodynamic diameter (MMAD) porous formulations through a simple aerosol device. These powders are made through a spray dry process and have the potential for sustained release. These large porous particles have a MMAD similar to smaller and denser particles, but because of their size they have less surface energy. Another example of this is PulmoSphere (Novartis Pharma) technology (Fig. 7), where engineered hollow and porous particles are inhaled using a simple inhaler device. Both ciprofloxacin and tobramycin, antibiotics used to treat airway infections, have been developed as an inhalation powder using this device. Studies suggest that tobramycin inhalation powder at $112 \mathrm{mg}$ is roughly equivalent to tobramycin by jet nebulization solution at a dose nearly 3 times greater. ${ }^{14}$

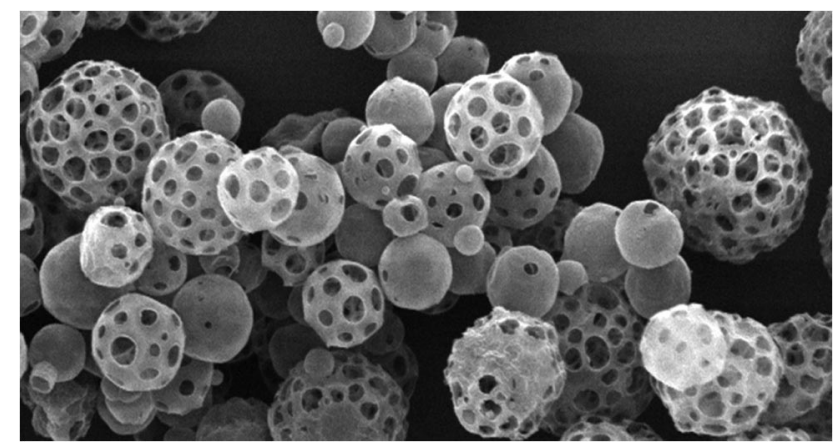

Fig. 7. PulmoSpheres are large, engineered, hollow, and porous particles with low surface energy and a mass median aerodynamic diameter similar to smaller and denser particles. These can be delivered using a very simple dry-powder inhaler. (Courtesy of Novartis Pharma.)

\section{Novel Medications}

A number of factors determine which medications will be given as an aerosol. By Sutton's law ("go where the money is"), the disease being treated is usually an airway disease, the medication can be aerosolized without degradation, it is effective at the airway surface, and the medication often has greater adverse effects when administered systemically. Medications for systemic administration can be delivered by using an ultra-fine aerosol targeted to the alveolar surface, where they can be rapidly absorbed. Recombinant proteins or complementary DNA for gene therapy can also be delivered to the airway (Table 2).

\section{Aerosol Antibiotics}

Recognizing that pneumonia, $\mathrm{COPD}$, and $\mathrm{CF}$ are all associated with airway infection, antibiotics have been delivered by aerosol for more than 60 years. ${ }^{15}$ Antibiotics for aerosol delivery generally are toxic at high systemic doses and they have concentration-dependent kinetics (Table 3). Examples include the quinolones and the aminoglycosides. Aerosolization can deliver a high concentration of antibiotic to the proximal airway, with minimal systemic absorption or toxicity. The patients most likely to benefit from aerosol antibiotics are those who require frequent courses of therapy, with a high airway burden of difficult to treat bacteria. Aerosol antibiotics do not penetrate to the most involved deep lung, particularly when the airways are full of pus, as in CF. Therefore, although high concentrations of antibiotics are present at the proximal airway, this concentration decreases as a gradient as one gets deeper in the airway and in the transitional airways, where the antimicrobial concentration is not high enough to kill resistant organisms; this will induce resistance. ${ }^{16}$ Antibiotic aerosols can also be irritating and produce bronchospasm and cough. 
Table 2. Novel Drugs for Aerosol Delivery

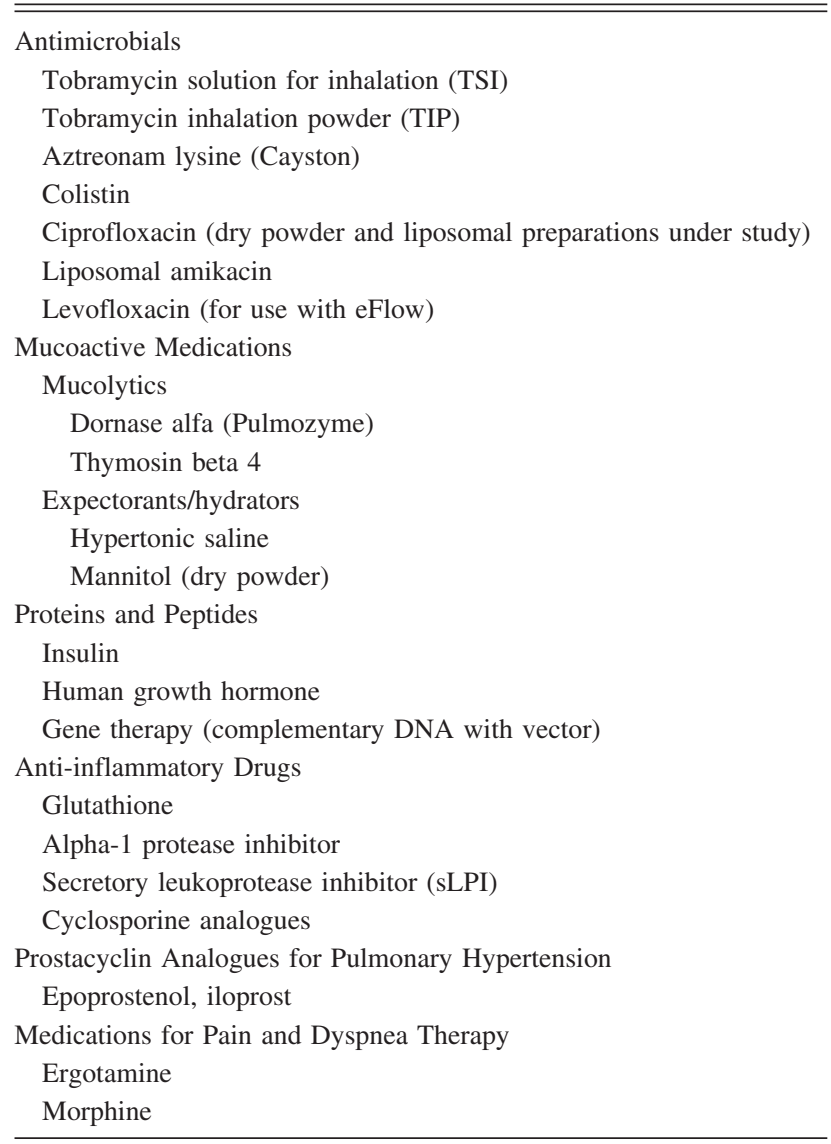

Some of the first antimicrobials used as aerosols were the aminoglycosides. When administered systemically there is a risk of renal dysfunction and hearing loss. Aerosol administration reduces but does not eliminate these risks. ${ }^{17}$ The first commercially available antibiotic for aerosol administration was tobramycin solution for inhalation (or TOBI), approved for the therapy of CF lung disease. Tobramycin solution for inhalation by jet nebulization at a dose of $300 \mathrm{mg}$ twice daily improves pulmonary function, reduces the risk of infectious exacerbation, and decreases the need for hospital intravenous therapy. ${ }^{18}$ Because antibiotic resistance is time dependent, it was thought that by administering the aerosol over 28-day cycles (28 days on and 28 days off) the bacteria would be less likely to develop resistance. Nevertheless, antimicrobial resistance continues to increase and is time dependent; but resistance will reverse if the drug is stopped for a sufficiently long duration. ${ }^{19}$ Although the risk of renal dysfunction and hearing loss are decreased, these are not eliminated by aerosol administration. ${ }^{20}$ Patients who receive inhaled gentamicin have nephrotoxicity related to the cumulative dose. ${ }^{17} \mathrm{Cur}$ rently available aerosolized antibiotics include tobramycin solution for inhalation, aztreonam, colistin (which is widely used in Europe), and several antiviral agents. Many other
Table 3. Desirable Characteristics for an Aerosol Antibiotic

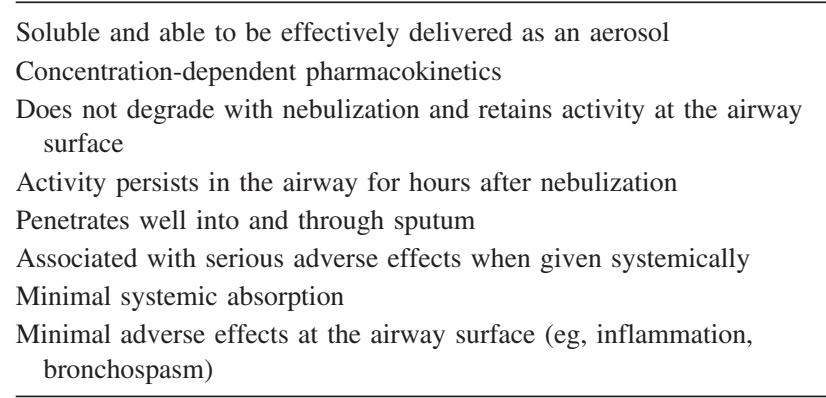

antimicrobials are being developed for aerosol use, including the quinolones ciprofloxacin and levofloxacin, the aminoglycosides gentamicin and neomycin, anti-fungal agents, and others.

Ventilator-associated tracheitis and ventilator-associated pneumonia (VAP) can be problems for patients who require intubation and mechanical ventilation. In the last decade there have been vigorous efforts to reduce the prevalence of these intensive care unit (ICU) acquired infections, using VAP bundles that include upright posturing, oral hygiene, closed suctioning, and the judicious use of antibiotics. There is controversy regarding the effectiveness of aerosol antibiotics in preventing VAP or treating established tracheitis and pneumonia, although the few published clinical trials suggest about a 30\% reduction in VAP in persons at risk given prophylactic antibiotic aerosol. ${ }^{21}$

Other potential uses for aerosolized antimicrobials under investigation include adjunctive therapy for the treatment of extensively resistant tuberculosis, the use of aerosolized pentamidine to treat Pneumocystis jiroveci pneumonia, and the development of novel antiviral agents for the prevention and treatment of seasonal influenza. ${ }^{22}$

\section{Mucoactive Medications}

The term "mucoactive medication" is a general classification to describe medications that are meant to influence mucus secretion or mucus clearance. ${ }^{23}$ Mucolytics are a type of mucoactive drug that breaks down polymer bonds of mucins (classic mucolytics) or the secondary polymers of DNA and filamentous (F-) actin (peptide mucolytics). The rationale for using mucolytics is the belief that decreasing mucus viscosity will improve clearance. When mucus adheres to the ciliated epithelium, a mucolytic may dissolve the attachments and improve ciliary and cough clearance. In general, however, secretions that are too thin are not as well cleared by cough as those that are more viscous. Thick secretions are better able to respond to the high-velocity air flow that is essential for an effective cough. ${ }^{24}$ Classic mucolytics such as $\mathrm{N}$-acetylcysteine 
reduce the disulfide bonds that linearly oligomerize gel forming mucin monomers. However, aerosol $\mathrm{N}$-acetylcysteine has never been shown to be effective for the treatment of any form of lung disease. Randomized controlled studies in $\mathrm{COPD}^{25}$ or $\mathrm{CF}^{26}$ showed no benefit from using acetylcysteine. CF sputum contains very little intact mucin and is more like pus. ${ }^{27}$ Acetylcysteine could be damaging to the $\mathrm{CF}$ airway because mucin is important for protecting the airway surface. Acetylcysteine is irritating, with a pKa of 2.2. It induces a cough and this may be its primary beneficial effect. Oral acetylcysteine is an antioxidant, but it has no mucolytic properties, as it is readily inactivated at the airway surface.

Dornase alfa (Pulmozyme, Genentech, South San Francisco, California) is the only approved peptide mucolytic for the treatment of CF. Dornase disrupts DNA polymers that form the secondary DNA and F-actin polymer network in CF sputum. Dornase has been available for more than a decade and is demonstrated to improve pulmonary function and reduce the frequency of CF respiratory tract exacerbations. ${ }^{28}$ Actin depolymerizing agents can also reduce the secondary polymer network, and these are synergistic with dornase. Among these is thymosin $\beta-4$, which appears to act not only as a mucolytic but may have antiinflammatory properties. ${ }^{29}$ There are few DNA polymers in asthma, COPD, plastic bronchitis, or pneumonia sputum, so dornase is not indicated for treating these diseases and has not been shown to be effective. ${ }^{30}$

Expectorants and mucokinetics include drugs that are sometimes loosely referred to as "airway hydrators." These medications act by increasing ion and water transport across the epithelium, and they also induce mucin secretion and stimulate ciliary beating. ${ }^{31}$ It is probable that stimulation of mucin and cough is more important for airway hygiene than the hydrating effects. These medications include hyperosmolar saline and dry-powder mannitol.

The Australian National CF Hypertonic Saline study showed a significant improvement in $\mathrm{FEV}_{1}$ in subjects with $\mathrm{CF}$ and fewer pulmonary exacerbations, when compared to normal saline. ${ }^{32}$ Small studies suggest that hypertonic saline may not be as effective as dornase alfa in improving $\mathrm{FEV}_{1}$ in persons with CF. ${ }^{33}$ Hyperosmolar saline can irritate the airway and cause bronchospasm, so it is usually administered along with a $\beta$ agonist. Inhaled dry-powder mannitol has been shown to be effective in improving pulmonary function in persons with $\mathrm{CF}$ and is tolerated at least as well as hyperosmolar saline. ${ }^{34}$ The improvement in pulmonary function with mannitol appears to be sustained for at least 18 months.

\section{Aerosol Surfactants}

In airways diseases such as CF, ARDS, meconium aspiration, and severe asthma, there is significant surfactant breakdown. ${ }^{35}$ Surfactant mobilizes secretions as a mucokinetic or abhesive medication, and not as a mucolytic. There are few clinical data on the use of surfactant aerosol, in part due to the difficulty of nebulizing liquid surfactant into the airway. With high-velocity air flow, liquid surfactant foams and has high viscosity. In vitro studies suggest that surfactant and perfluorocarbons can be aerosolized using an inhalation catheter. ${ }^{36}$ Surfactants can also stabilize airways and may have anti-inflammatory properties.

CF sputum is now known not to be very thick or viscous, but it is very sticky. ${ }^{23}$ This is due to the DNA content and probably to decreased hydration. Degradation of airway surfactant in the CF airway can also reduce mucociliary coupling. Surfactant can reduce sputum stickiness, and the aerosolization of surfactant has been shown to improve pulmonary function in patients with COPD. ${ }^{37}$ Surfactant may be effective for secretion mobilization in the intubated and ventilated patient, where there is incomplete airway humidification.

\section{Anti-inflammatory Drugs}

The most commonly used anti-inflammatory medications are inhaled corticosteroids (ICS) for the treatment of asthma. A number of other drugs have been studied as aerosols, including recombinant secretory leukoprotease inhibitor, anti-neutrophil elastase, and alpha-1 antiprotease. ${ }^{38}$ These can decrease the activity of serine proteases, such as neutrophil elastase, in the chronically inflamed airway. Antioxidants such as glutathione and recombinant superoxide dismutase have also been administered as aerosols. Aerosolized glutathione is currently being studied as adjuvant therapy for the treatment of CF lung disease. ${ }^{39}$

Cyclosporine can be efficiently nebulized and may protect against airway inflammation and allergic challenge..$^{40}$ Aerosolized cyclosporine may also have a role in graft preservation following lung transplantation. ${ }^{41}$

\section{Aerosolized Peptides and Proteins}

Peptides have been delivered as aerosols both to treat airway and systemic disease. ${ }^{42}$ Pulmonary alveolar proteinosis is a rare disease caused by failure of alveolar macrophages to ingest and degrade surfactant. In adults it is usually due to antibodies produced against granulocyte macrophage colony stimulating factor, a cytokine that is essential for macrophage maturation and function. With reduced granulocyte macrophage colony stimulating factor function, macrophages can ingest surfactant but fail to degrade it. Aerosolized granulocyte macrophage colony stimulating factor has shown promise in treating this disease by overcoming the antibodies or the receptor abnormality and triggering macrophage maturation. ${ }^{11}$ 
Proteins have also been administered by aerosol for systemic delivery. For these to be effective the proteins must have aerodynamic behavior that permits them to deposit in the alveolus, where they can cross the very thin bloodairway barrier and enter the systemic circulation. ${ }^{43}$ This involves the production of ultra-fine particles inspired using flow-regulated inhalation that maximizes alveolar deposition. Among the first of these to be administered as an aerosol was insulin, in $1925 .{ }^{44}$ Diabetes affects more than 200 million people globally, insulin has a narrow therapeutic index, and there is a wealth of data showing that insulin is effective when delivered as an aerosol. Aerosol insulin was briefly marketed by Pfizer as Exubera, and is still being developed by Mannkind with a smaller and more portable aerosol device. In the ICU setting it may become possible to deliver aerosol peptides to modify the dysregulated inflammatory response characteristic of many severe illnesses.

Other large peptides for airway delivery might include gene-transfer therapy using complimentary DNA delivered as an aerosol in a vector package to the affected cells. ${ }^{45}$ This is the strategy that is currently being taken for the development and delivery of gene-transfer therapy for the treatment of $\mathrm{CF}$.

\section{Prostacyclin Analogues for Pulmonary Hypertension}

There are a number of medications available to treat pulmonary hypertension, including drugs that increase nitric oxide, inhibit endothelin, or activate phosphodiesterase. Among these are the prostacyclin analogues epoprostenol and iloprost, which are well accepted as nebulized medications for treating severe pulmonary hypertension. ${ }^{46}$ Inhaled iloprost showed greater safety than the intravenous preparation with preferential vasodilatation in the pulmonary circulation. A drawback of inhaled iloprost is the short hemodynamic effect requiring frequent dosing. Prostacyclin analogues with longer half-life (eg, treprostinil) and controlled release formulations are in clinical development.

\section{Medications for Treating Pain and Dyspnea}

Migraine headache affects 30 million people in the United States, and for about $10 \%$ of these patients the suffering is chronic and incapacitating. Ergotamine is an ergopeptine, structurally similar to neurotransmitters like serotonin and dopamine. It is a vasoconstrictor that is effective for treating acute migraine attacks; however, it is used less commonly than other migraine relievers because of adverse effects, including gastrointestinal-tract irritation, angina, drowsiness, dizziness, and rebound headache. Ergotamine has been delivered as an aerosol using a novel breath- synchronized inhaler and is in clinical trials for migraine relief. ${ }^{47}$

Morphine has been administered by nebulization for the treatment of severe dyspnea and intractable cough, especially in persons with cancer receiving palliative care. Morphine aerosol can exacerbate hypoventilation and carbon dioxide retention, so it must be administered with the same care as systemic opioids. ${ }^{48}$

\section{Aerosol Administration During Mechanical Ventilation}

Although medications are frequently administered by aerosol to patients receiving mechanical ventilation, this is an area that is controversial and rapidly evolving. In the ICU the most commonly administered aerosol medications are mucolytics, ICS, and bronchodilators given to treat a wide variety of illness beyond their intended use. There is no clear evidence that aerosol bronchodilators or ICS benefit patients with ARDS, bronchiectasis, pneumonia, croup, VAP, bronchiolitis, or respiratory failure, and these drugs carry risks. $\beta$ agonists can remove intrinsic airway tone, leading to atelectasis in airways that are not well supported by cartilage, ${ }^{49}$ and systemic absorption can have adverse cardiac effects. ICS potentially can increase the risk of pneumonia. Even in persons with asthma, there are data suggesting that giving high doses of $\beta$ agonist and ICS to patients on mechanical ventilation is of limited value at best and may contribute to asthma morbidity and mortality. ${ }^{50}$

Mucolytics such as dornase alfa or acetylcysteine are of no proven value to patients on mechanical ventilators. $\mathrm{Mu}-$ colytics are effective only if patients are able to generate an effective cough. Patients requiring mechanical ventilation have impaired airway clearance, both because of mucociliary dysfunction and because air is being forced into their airway on inspiration, driving secretions deeper into the airways. This is only made worse when secretions are thinned.

When medications are administered during mechanical ventilation, many factors influence how well these are deposited in the airway, including airway characteristics (presence of inflammation and mucus), inspiratory flow, humidification of the ventilator circuit, placement of the aerosol device, timing of aerosol administration to inhalation, and the aerosol device chosen. There is less hydroscopic growth of inhaled particles and thus less rainout when aerosols are administered into a dry circuit, although this usually means temporarily interrupting humidification. There are a variety of aerosol devices that can be placed in-line or as part of the ventilator. Many of these factors have been studied in simulated pediatric lung models during mechanical ventilation and are summarized in a recent paper. ${ }^{51}$ These authors conclude that nebulizer place- 


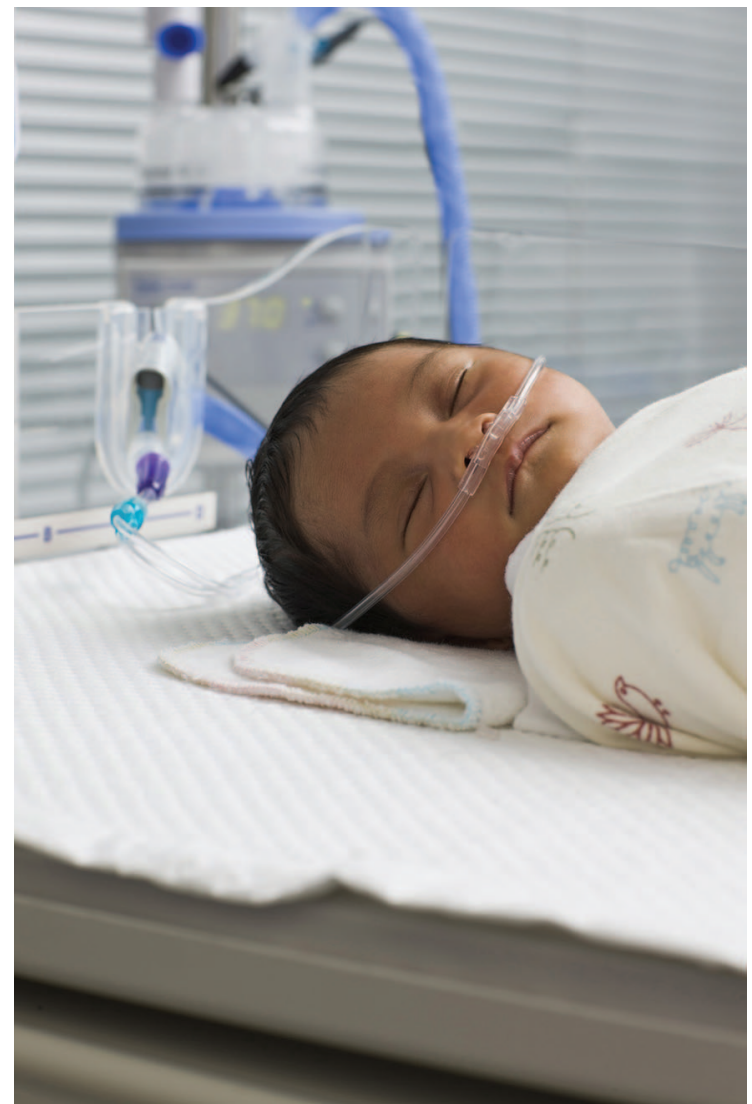

Fig. 8. Devices are being developed to deliver aerosol therapy using high-flow nasal cannula. This is expected to be particularly useful. (Courtesy of Fisher \& Paykel Healthcare.)

ment before the humidifier using a vibrating-mesh nebulizer and a decreased bias flow can improve delivery of aerosol to a pediatric lung model.

\section{Aerosol Delivery Via High-Flow Nasal Cannula}

Noninvasive mechanical ventilation and high-flow nasal oxygen delivery (Fig. 8) can reduce the need for intubation in some critically ill infants and children. In vitro studies have evaluated aerosol output through nasal cannula. Using a driving flow of $3 \mathrm{~L} / \mathrm{min}$ and a breathing simulator, the cannula output ranged from $8.4 \%$ to $18.6 \%$ of the loaded dose..$^{52}$ In vitro studies of enhanced condensational growth also suggest potential ways to enhance lung delivery of nasal aerosols during noninvasive ventilation..$^{53}$ Although much of the work to date has been done adapting existing aerosol devices to nasal cannula, it is likely that greater benefit will come from nasal-flow-specific aerosol devices.

\section{Adherence to Therapy}

For many years we relied on conventional jet nebulizers, dry-powder inhalers, and pMDIs as our standard of
Table 4. Techniques to Improve Adherence to Aerosol Medications

Clear written explanation and demonstration given at the time the medication or device is prescribed

Have patient bring medication to every appointment and check the patient's technique at each visit

Ask the patient specifically about adherence, problems with the medication or device, and unanswered questions

Follow up on unfilled prescriptions and refills

Minimize the number of different medications and devices used by the patient: keep it simple

Parents need to take primary responsibility for medication administration for their children living at home, regardless of the child's age

care..$^{54}$ There are many novel technologies that will enable precise drug dosing and targeting (Table 4). However, the most sophisticated devices and drugs still rely on the patient being willing to use the device and drug and to use them appropriately. ${ }^{55}$ Adherence to aerosols appears to be at best $50 \%$, and unstable asthma is often due to poor adherence. ${ }^{56}$ It is imperative that the respiratory therapist become the education expert for ensuring that patients are using their medication appropriately and wisely. It is a therapist who administers drugs and observes patients using devices in the clinic, in the pulmonary function lab, and in hospital. Each time a therapist administers medication to the patient is an opportunity for teaching and for reinforcing the message of adherence.

\section{Summary}

There have been dramatic advances, not only in the medications that are being administered by aerosol, but in the devices available for aerosol delivery. We have moved well beyond $\beta$ agonists, ICS, and mucolytics. This has been matched by dramatic improvements in aerosol generation and mechanical ventilation technology. In many cases the technology has outpaced our knowledge of the safety and effectiveness of these medications when given to patients in the ICU. Over the next 5 years there will be studies to optimize the use of these drugs and devices for specific indications (eg, surfactants, aerosol antibiotics) and for specific applications such as high-flow nasal delivery, delivery during noninvasive mechanical ventilation, and delivery to the intubated and mechanically ventilated patient. Large coordinated critical care research networks provide the ability to conduct well controlled clinical trials to determine the patient population, medications, dosage and duration of therapy, appropriate devices, and potential risks of these new therapies for the critically ill infant and child.

\section{REFERENCES}

1. Wright BM. A new nebulizer. Lancet 1958;2(7036):24-25. 
2. Freedman T. Medihaler therapy for bronchial asthma: a new type of aerosol therapy. Postgrad Med 1956;20(6):667-673.

3. Takizawa H. Recent development of drug delivery systems for the treatment of asthma and related disorders. Recent Pat Inflamm Allergy Drug Discov 2009;3(3):232-239.

4. Dalby R, Spallek M, Voshaar T. A review of the development of Respimat Soft Mist Inhaler. Int J Pharm 2004;283(1-2):1-9.

5. Hochrainer D, Holz H, Kreher C, Scaffidi L, Spallek M, Wachtel H. Comparison of the aerosol velocity and spray duration of Respimat Soft Mist inhaler and pressurized metered dose inhalers. J Aerosol Med 2005;18(3):273-282.

6. Brand P, Hederer B, Austen G, Dewberry H, Meyer T. Higher lung deposition with Respimat Soft Mist inhaler than HFA-MDI in COPD patients with poor technique. Int J Chron Obstruct Pulmon Dis 2008; 3(4):763-770.

7. van Noord JA, Cornelissen PJ, Aumann JL, Platz J, Mueller A, Fogarty C. The efficacy of tiotropium administered via Respimat Soft Mist Inhaler or HandiHaler in COPD patients. Respir Med 2009;103(1):22-29.

8. Dhand R. Nebulizers that use a vibrating mesh or plate with multiple apertures to generate aerosol. Respir Care 2002;47(12):1406-1416; discussion 1416-1418.

9. Retsch-Bogart GZ, Quittner AL, Gibson RL, Oermann CM, McCoy KS, Montgomery AB, Cooper PJ. Efficacy and safety of inhaled aztreonam lysine for airway pseudomonas in cystic fibrosis. Chest 2009;135(5):1223-1232.

10. Brand P, Friemel I, Meyer T, Schulz H, Heyder J, Häubetainger K. Total deposition of therapeutic particles during spontaneous and controlled inhalations. J Pharm Sci 2000;89(6):724-731.

11. Luisetti M, Kroneberg P, Suzuki T, Kadija Z, Muellinger B, Campo I, et al. Physical properties, lung deposition modeling, and bioactivity of recombinant GM-CSF aerosolised with a highly efficient nebulizer. Pulm Pharmacol Ther 2011;24(1):123-127.

12. Rubin BK. Bye-bye, blow-by (editorial). Respir Care 2007;52(8):981.

13. Amirav I, Balanov I, Gorenberg M, Groshar D, Luder AS. Nebuliser hood compared to mask in wheezy infants: aerosol therapy without tears! Arch Dis Child 2003;88(8):719-723.

14. Geller DE, Konstan MW, Smith J, Noonberg SB, Conrad C. Novel tobramycin inhalation powder in cystic fibrosis subjects: pharmacokinetics and safety. Pediatr Pulmonol 2007;42(4):307-313.

15. Potter BP. Aerosol antibiotic therapy in suppurative diseases of the lung and bronchi. Dis Chest (now Chest) 1949;15(4):436-448.

16. Rubin BK. Aerosolized antibiotics for non-cystic fibrosis bronchiectasis. J Aerosol Med Pulm Drug Deliv 2008;21(1):71-76.

17. Ring E, Eber E, Erwa W, Zach MS. Urinary N-acetyl- $\beta$-D-glucosaminidase activity in patients with cystic fibrosis on long term gentamicin inhalation Arch Dis Child 1998;78(6):540-543.

18. Ramsey BW, Pepe MS, Quan JM, Otto KL, Montgomery AB, Williams-Warren J, et al. Intermittent administration of inhaled tobramycin in patients with cystic fibrosis. Cystic Fibrosis Inhaled Tobramycin Study Group. N Engl J Med 1999;340(1):23-30.

19. Smith AL, Ramsey BW, Hedges DL, Hack B, Williams-Warren J, Weber A, et al. Safety of aerosol tobramycin administration for 3 months to patients with cystic fibrosis. Pediatr Pulmonol 1989;7(4):265-271.

20. Hoffmann IM, Rubin BK, Iskandar SS, Schechter MS, Nagaraj SK, Bitzan MM. Acute, renal failure in cystic fibrosis: association with inhaled tobramycin therapy. Pediatr Pulmonol 2002;34(3):375-377.

21. MacIntyre N, Rubin BK. Should aerosolized antibiotics be administered to prevent or treat ventilator associated pneumonia in patients who do not have cystic fibrosis? Respir Care 2007;52(4):416-421; discussion 421-422.

22. Smith DJ, Bot S, Dellamary L, Bot A. Evaluation of novel aerosol formulations designed for mucosal vaccination against influenza virus. Vaccine 2003;21(21-22):2805-2812.
23. Voynow JA, Rubin BK. Mucus, mucins, and sputum Chest 2009; 135(2):505-512.

24. Rubin BK. Mucolytics, expectorants, and mucokinetic medications. Respir Care 2007;52(7):859-865.

25. Decramer M, Rutten-van Mölken M, Dekhuijzen PN, Troosters T, van Herwaarden C, Pellegrino R, et al. Effects of N-acetylcysteine on outcomes in chronic obstructive pulmonary disease (Bronchitis Randomized on NAC Cost-Utility Study, BRONCUS): a randomised placebo-controlled trial. Lancet 2005;365(9470):1552-1560.

26. Duijvestijn YC, Brand PL. Systematic review of N-acetylcysteine in cystic fibrosis. Acta Paediatr 1999;88(1):38-41.

27. Henke M, Renner A, Huber RM, Seeds MC, Rubin BK. MUC5AC and MUC5B mucins are decreased in cystic fibrosis airway secretions. Am J Respir Cell Mol Biol 2004;31(1):86-91.

28. Fuchs HJ, Borowitz DS, Christiansen DH, Morris EM, Nash ML, Ramsey BW, et al. Effect of aerosolized recombinant human DNase on exacerbations of respiratory symptoms and on pulmonary function in patients with cystic fibrosis. The Pulmozyme Study Group. N Engl J Med 1994;331(10):637-642.

29. Rubin BK, Kater AP, Goldstein AL. Thymosin $B 4$ sequesters actin in cystic fibrosis sputum and decreases sputum cohesivity in vitro. Chest 2006;130(5):1433-1440.

30. Rubin BK. Who will benefit from DNase? Pediatr Pulmonol 1999; 27(1):3-4.

31. Kishioka C, Okamoto K, Kim J-S, Rubin BK. Hyperosmolar solutions stimulate mucus secretion in the ferret trachea. Chest 2003; 124(1):306-313.

32. Elkins MR, Robinson M, Rose BR, Harbour C, Moriarty CP, Marks GB, et al; National Hypertonic Saline in Cystic Fibrosis (NHSCF) Study Group. A controlled trial of long-term inhaled hypertonic saline in patients with cystic fibrosis. N Engl J Med 2006;354(3): 229-240.

33. Suri R, Metcalfe C, Lees B, Grieve R, Flather M, Normand C, et al. Comparison of hypertonic saline and alternate-day or daily recombinant human deoxyribonuclease in children with cystic fibrosis: a randomised trial. Lancet 2001;358(9290):1316-1321.

34. Wills PJ. Inhaled mannitol in cystic fibrosis. Expert Opin Investig Drugs 2007;16(7):1121-1126.

35. Fuloria M, Wu Y, Brandt ML, Rubin BK. Effect of meconium on the surface properties of perflubron. Pediatr Crit Care Med 2004;5(2): 167-171.

36. Murgia X, Gastiasoro E, Mielgo V, Alvarez-Diaz F, Lafuente H, Valls-i-Soler A, et al. Surfactant and perfluorocarbon aerosolization by means of inhalation catheters for the treatment of respiratory distress syndrome: an in vitro study. J Aerosol Med Pulm Drug Deliv 2011;24(2):81-87.

37. Anzueto A, Jubran A, Ohar JA, Piquette CA, Rennard SI, Colice G, et al. Effects of aerosolized surfactant in patients with stable chronic bronchitis. A prospective randomized controlled trial. JAMA 1997; 278(17):1426-1431.

38. Brand P, Schulte M, Wencker M, Herpich CH, Klein G, Hanna K, Meyer T. Lung deposition of inhaled alpha1-proteinase inhibitor in cystic fibrosis and alpha1-antitrypsin deficiency. Eur Respir J 2009; 34(2):354-360.

39. Snyder AH, McPherson ME, Hunt JF, Johnson M, Stamler JS, Gaston B. Acute effects of aerosolized S-nitrosoglutathione in cystic fibrosis. Am J Respir Crit Care Med 2002;165(7):922-926.

40. Eckstein JW, Fung J. A new class of cyclosporin analogues for the treatment of asthma. Expert Opin Invest. Drugs 2003;12(4):647-653.

41. Groves S, Galazka M, Johnson B, Corcoran T, Verceles A, Britt E, et al. Inhaled cyclosporine and pulmonary function in lung transplant recipients. J Aerosol Med Pulm Drug Deliv 2010;23(1):31-39. 
42. Rubin BK. Experimental macromolecular aerosol therapy. Respir Care 2000;45(6):684-694.

43. Gonda I. Systemic delivery of drugs to humans via inhalation. J Aerosol Med 2006;19(1):47-53.

44. Gaensslen M. Über inhalation von insulin. Klin Wochenschr 1925; 4(2):71-72. Article in German.

45. Laube BL. The expanding role of aerosols in systemic drug delivery, gene therapy, and vaccination. Respir Care 2005;50(9):1161-1174; discussion 1174-1176.

46. Gessler T, Seeger W, Schmehl T. Inhaled prostanoids in the therapy of pulmonary hypertension. J Aerosol Med Pulm Drug Deliv 2008;21(1): $1-12$.

47. Armer TA, Shrewsbury SB, Newman SP, Pitcairn G, Ramadan N. Aerosol delivery of ergotamine tartrate via a breath-synchronized plumecontrol inhaler in humans. Curr Med Res Opin 2007;23(12):3177-3187.

48. Foral PA, Malesker MA, Huerta G, Hilleman DE. Nebulized opioids use in COPD. Chest 2004;125(2):691-694.

49. Panitch HB, Keklikian EN, Motley RA, Wolfson MR, Schidlow DV. Effect of altering smooth muscle tone on maximal expiratory flows in patients with tracheomalacia. Pediatr Pulmonol 1990;9(3):170-176.
50. Rubin BK, Pohanka V. Beyond the guidelines: fatal and near-fatal asthma. Paediatr Respir Rev 2011 (in press).

51. Ari A, Atalay OT, Harwood R, Sheard MM, Aljamhan EA, Fink JB. Influence of nebulizer type, position, and bias flow on aerosol drug delivery in simulated pediatric and adult lung models during mechanical ventilation. Respir Care 2010;55(7):845-851.

52. Bhashyam AR, Wolf MT, Marcinkowski AL, Saville A, Thomas K, Carcillo JA, Corcoran TE. Aerosol delivery through nasal cannulas: an in vitro study. J Aerosol Med Pulm Drug Deliv 2008;21(2):181-188.

53. Longest PW, Tian G, Hindle M. Improving the lung delivery of nasally administered aerosols during noninvasive ventilation: an application of enhanced condensational growth (ECG). J Aerosol Med Pulm Drug Deliv 2011;24(2):103-118.

54. Dolovich MB, Ahrens RC, Hess DR, Anderson P, Dhand R, Rau JL, et al. Device selection and outcomes of aerosol therapy: evidencebased guidelines. Chest 2005;127(1):335-371.

55. Rubin BK. What does it mean when a patient says, "My asthma medication isn't working?". Chest 2004;126(3):972-981.

56. Rubin BK. Adherence to asthma therapy: the "blocked receptor". Pediatr Pulmonol 2004;26(Suppl):36-37.

\section{Discussion}

DiBlasi: Say you are mentoring a new fellow or respiratory care student and you'd like to teach him or her how to properly administer a pMDI with spacer, and a jet nebulizer. What are some essential guidelines you would provide to a person who's never done it before?

Rubin: I would put him with Jim Norton, who's an RT [respiratory therapist] and a superb educator. We leave it to the RT educators to do the aerosol education. They do it better than I do. If I were to do it, I would take out the device, show it to the fellow, make sure the device is a new one, show the dose counter, shake it up, have him put it in the holding chamber (we use a holding chamber for nearly everybody), actuate it, remind him that they have about 20 seconds at most between actuation and inhalation, have them put it into their mouth, since we're using a placebo, and first have them inhale far too fast so that it all goes into their oropharynx, and then teach them to breathe it in very slowly. You've got to sit there and watch that they are breathing in and that they're breathing in slowly.
For the small infant, I'd say you use a mask and make sure that it's comfortable on the face and the child is comfortable. We use the AeroChamber with Flow-Vu in our institution, so make sure the Flow-Vu (which allows you to see the inhalation valve) opens, give them 5 or 6 breaths to clear the device, shake it up again, and do a second inhalation.

DiBlasi: Excellent, thank you.

Myers: Bruce, you talked about some very exotic-probably expensive-devices that are probably going to be reserved for exotic expensive drugs. But delivery is still techniquedependent and user-dependent, and it was obvious with inhaled insulin that they went around the RTs as far as medication delivery, because it wasn't a respiratory medication. So as we get to more exotic drugs, what role does the RT play when it comes to delivery devices that are not for respiratory drugs?

Rubin: I think therapists understand the physiology better than anybody in our hospital. Licensed respiratory therapists should be the professionals and the educators. It's the role of the therapist to know these devices, know the pitfalls, know how to use them, and to make sure the patient understands them. You don't have to go crazy giving way too much information, but you do need to know that the important stuff is important.

As these devices come onto the market, the therapist should know what you shouldn't be putting in them, how to use them, how to clean them, and should make sure that every time the patient comes back that they spend time with the therapists reviewing that they know how to use the device. That is an important part of what we do.

You can take the most expensive fancy drug and most expensive fancy nebulizer, but they are not going to work unless they're being used appropriately. Education is the key. And I think the therapist is the key for education for all these devices and drugs. That means therapists will have to learn about these new drugs, devices, and diseases, because it's the therapist who understands the physiology and how to deposit those drugs in the lung.

Branson: Bruce, in the trauma ICU, where patients often have acute kidney injury because of trauma or ischemia, and then need a computed tomography with dye, and now they have marginal renal function, we routinely give aerosolized tobramycin in those patients who have VAP. We don't use TOBI, we use the intravenous version. 
Is that a good idea, or does it need further study?

Rubin: Tobramycin and gentamicin (aminoglycosides) are concentration dependent or AUC/MIC [area under the curve/minimum inhibitory concentration] killers. Renal toxicity is based on the ability of the kidneys to clear the drug, and thus the trough level. Neonates have much slower clearance. For a specific patient, if you're giving the drug by aerosol and they have compromised renal function, you need to measure their levels. You need to make sure that the trough is not going up, and you need to make sure that the drug is being eliminated. There is systemic absorption of these medications.

We reported ${ }^{1}$ a few years ago on a patient of mine who was an adolescent with $\mathrm{CF}$, on no nephrotoxic drugs other than TOBI, and for some reason was getting significant systemic absorption, and went into renal failure that fortunately reversed. The main advantage of TOBI is lack of preservatives. I think the preservative is inflammatory in some patients. I would monitor aminoglycoside level, and if it starts drifting over 1 , hold the dose.

1. Hoffmann IM, Rubin BK, Iskandar SS, Schechter MS, Nagaraj SK, Bitzan MM. Acute renal failure in cystic fibrosis: association with inhaled tobramycin therapy. Pediatr Pulmonol 2002;34(5):375-377.

Brown: I see administration of aerosols more frequently now in the neonatal ICU. Steroids seem to be coming more into favor, and in the neonatal ICU aerosol masks aren't used, so we see the use of blow-by technique which we all know is not so super. I've seen 2 different techniques: one where the therapist holds a medication nebulizer with tubing about an inch away from the patient's face. How much drug is that getting to the patient? I also see them connect a resuscitation mask and hold the mask gently onto the face. Do you think that's any better, or do you have any better suggestions?
Rubin: Blow-by does not deliver medication to the lower respiratory tract in any appreciable amount. Mark Everard showed ${ }^{1}$ years ago that by nebulizing a dose of cromoglycate against a manikin face with a mask and moving it one centimeter away (roughly $1 / 2$ an inch) the delivery dropped by $40 \%$, and it dropped by $85 \%$ at $2 \mathrm{~cm}$. Blow-by does not work; you may as well not nebulize the medication at all. Having a close-fitting mask will work, and potentially nasal cannula delivery may be an alternative delivery in some of these neonates. Studies show that ICS will reduce the development of chronic lung disease of the newborn. However, I see toddlers who had mild chronic lung disease (bronchopulmonary dysplasia) as a neonate still coming in on ICS at age 3 ! There are no data to support that.

1. Everard ML, Clark AR, Milner AD. Drug delivery from holding chambers with attached facemask. Arch Dis Child 1992; 67(5):580-585.

Brown: Just to agree with you, that's what I teach RTs, but I still see it done, so I wanted it published here in the Journal so I can walk it around.

Rubin: It was published ${ }^{1}$ in the Journal in 2007. The data were summarized in a one-page editorial that I wrote, called "Bye-bye, blow-by."

1. Rubin BK. Bye-bye, blow-by (editorial). Respir Care 2007;52(8):981.

Brown: Great. Do you have any recommendations as far as the ventilated neonate? About placement of the nebulizer?

Rubin: There are conflicting data. Jim Fink did some work showing that, at least in adults, moving it back away from the Y-piece gives better deposition. There are some suggestions that moving it as close as possible to the Y-piece may improve delivery, and shutting off the humidification may improve delivery.
Brown: It's a big question in the ICU, and has been for years. I read Jim's stuff, and sometimes we still don't quite have the answers.

Rubin: Agreed.

DiBlasi: There were 2 studies ${ }^{1,2}$ published in Respiratory CARE this year that tested the hypotheses that placement within the ventilator circuit, delivery modality, and aerosol delivery device may impact drug delivery differently in a test lung model, so I would invite you to evaluate those studies, because they're very insightful and I think they may actually change clinical practice for administering bronchodilators to mechanically ventilated patients.

One study ${ }^{1}$ was conducted using a premature infant, term-neonate, and small-child test-lung model. Albuterol was delivered via pMDI with a novel pediatric spacer during spontaneous breathing, manual resuscitation, and mechanical ventilation.

1. DiBlasi RM, Coppolo DP, Nagel MW, Doyle CC, Avvakoumova VI, Ali RS, Mitchell JP. A novel, versatile valved holding chamber for delivering inhaled medications to neonates and small children: laboratory simulation of delivery options. Respir Care 2010;55(4):419-426.

2. Ari A, Atalay OT, Harwood R, Sheard MM, Aljamhan EA, Fink JB. Influence of nebulizer type, position, and bias flow on aerosol drug delivery in simulated pediatric and adult lung models during mechanical ventilation. Respir Care 2010;55(7):845-851.

Rubin: What were the results?

DiBlasi: Well, like most in vitro studies, if you take humidification away, you double the medication delivery. It was no surprise that, in all the tested conditions, albuterol delivery was lowest during mechanical ventilation, but the measured total emitted mass was higher than that measured in other studies. There were very small differences in medication delivery between manual resuscitation and spontaneous breathing for each patient size. 
The other study, by Ari et al, compared drug delivery with a jet nebulizer versus a vibrating-mesh nebulizer at two locations in the ventilator circuit, and in adult and pediatric lung models. Overall, the vibrating-mesh nebulizer delivered more drug than the jet nebulizer in both positions. In the adult model there was a nearly 3 -fold increase in drug delivery when the vibrating-mesh nebulizer was moved from the patient Y-piece to a location between the ventilator and the humidifier. However, there were no significant differences between the two positions when the vibrating-mesh nebulizer was used in the pediatric lung model, possibly due to the smaller circuit size and less time for the circuit to function as a reservoir. Nonetheless, pediatric clinicians are using this strategy with vibrating-mesh nebulizer in the pediatric ICU, even though the positive findings were found only in the adult lung model.

Brown: I think each unit does things a little differently, so it's hard to extrapolate beyond your unit on something like using an MDI versus a vibrating-mesh nebulizer. Sometimes the details are different, such as what type of ventilators they have or whether they use continuous flow. Bruce, probably the number one question I get in the neonatal ICU is, can we deliver aerosol via nasal CPAP? And where should we put it? Can it go through a generator head? Will there be any aerosol left? They're looking for answers, and they don't like to take off the nasal CPAP, obviously.

Wiswell: I want to make a comment particularly for the therapists who work in the neonatal ICU. All the inhalation therapies-albuterol most commonly, steroids less frequentlythey don't work! Win Tin and I have done several reviews ${ }^{1,2}$ over the last several years concerning various aerosolized medication for neonates. There is limited to no efficacy. As we've discussed for the past 2 days, clinicians always feel they have to do something. We should adhere at all times to what Bruce said yesterday: "Don't just do something: stand there ... and think." People are reluctant to stand pat and not introduce new, albeit ineffective, therapies.

Frequently I'll come into the neonatal ICU and take over a service and have a patient who's been on albuterol for a month or two because it's thought to be good for the health of the baby's lungs. I will ask my colleagues and the respiratory therapists, in this patient have you shown this helps? Have you done any kind of serial pulmonary function testing? They typically have not. During use of the aerosol therapies, babies will have remained on essentially the same ventilator settings they were on before introducing the agent.

Unfortunately, aerosolized drugs are commonly used and continue to be used without really documenting efficacy. Granted, there will be some patients who occasionally respond to some of these drugs. Nevertheless, one has to assess the use of such therapies over a period of time to determine whether there's true improvement that you can relate directly to the therapy. There is potential for adverse effects with all the aerosolized agents. In general, the adjunctive aerosolized therapies that we have for respiratory disorders in neonatal ICUs don't work.

1. Wiswell TE, Tin W, Ohler K. Evidencebased use of adjunctive therapies to ventilation. Clin Perinatol 2007;34(1):191-204.

2. Tin W, Wiswell TE. Drug therapies in bronchopulmonary dysplasia: debunking the myths. Semin Fetal Neonatal Med 2009; 14(6):383-390

Brown: I agree with you, Tom. I used to judge the quality of a unit by how little nebulized therapy they were ordering. I still see albuterol ordered a lot, but I think you kind of contradicted what Bruce said about positive evidence on ICS.

Rubin: I just want to add to that that there are no data for many of these medications that are often used. I'm interested to see what will happen with ICS. There's a warning about albuterol and airway malacia. When you have acquired malacia, the airway is held open, in part, by muscle. The group in Pittsburgh has shown that you can worsen malacia significantly by giving aerosolized albuterol and relaxing this muscle. For patients with documented tracheomalacia, we avoid it: there's no benefit. 